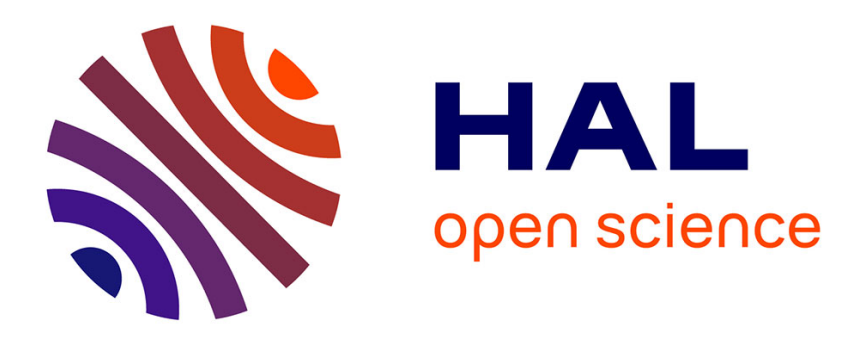

\title{
Collaboration and computer-assisted acquisition of a second language
}

Delphine Renié, Thierry Chanier

\section{To cite this version:}

Delphine Renié, Thierry Chanier. Collaboration and computer-assisted acquisition of a second language. Computer-Assisted Language Learning, 1995, 8 (1), pp.3-30. edutice-00000277

\section{HAL Id: edutice-00000277}

\section{https://edutice.archives-ouvertes.fr/edutice-00000277}

Submitted on 23 Nov 2003

HAL is a multi-disciplinary open access archive for the deposit and dissemination of scientific research documents, whether they are published or not. The documents may come from teaching and research institutions in France or abroad, or from public or private research centers.
L'archive ouverte pluridisciplinaire HAL, est destinée au dépôt et à la diffusion de documents scientifiques de niveau recherche, publiés ou non, émanant des établissements d'enseignement et de recherche français ou étrangers, des laboratoires publics ou privés. 


\title{
COLLABORATION AND COMPUTER-ASSISTED ACQUISITION OF A SECOND LANGUAGE.
}

\author{
Delphine Renié, Thierry Chanier \\ Laboratoire de Recherche sur le Langage, Département de Linguistique \\ Université Clermont 2, 34 avenue Carnot \\ 63000 Clermont-Ferrand, FRANCE. \\ Email: \{renie, chanier\}@cicc.univ-bpclermont.fr
}

Delphine Renié, Thierry Chanier. Collaboration and computer-assisted acquisition of a second language. Computer-Assisted Language Learning, 1995, 8 (1), pp.3-30.

Abstract: In the last few years, the community working on Computer Assisted Learning has started considering a different type of learning as an alternative to traditional ones: collaborative learning (or cooperative learning). We are addressing the question of defining how collaboration could be beneficial to a computer environment for language learning. In order to answer that question , we refer to various research fields, such as Applied linguistics, Psychology of Education, Artificial Intelligence and Education. From thereon we propose an application of collaborative learning to one particular domain of the second language: interrogative sentences in French.

Key-words: collaboration, interaction, learning of pragmatics, second language acquisition, computer-assisted language learning.

\section{Collaboration in acquisition.}

Collaboration is a fashionable topic nowadays in the fields of Computer Assisted Learning (CAL) and Artificial Intelligence and Education (AIEd) (Dillenbourg \& Self 1991-92; Terveen 1993). Work done in these fields has been relying largely on studies in Psychology of Education (Vygotsky 1978; O'Malley 1992; Blaye, Light \& Rubtsov 1992, for instance). The more specialised community of Computer Assisted Language Learning is not represented in this trend, yet we think it could benefit from a collaborative mode of learning. In this paper, we attempt to isolate the conditions under which collaboration would be favourable 
to the acquisition of a second language. The element of the second language to be acquired is the French interrogative which can take various forms in French, according to the various semantic and pragmatic parameters defining the communicative situation. In order to support the acquisition of both linguistic and pragmatic parameters, we advocate an interactive form of learning. We rely here on several studies conducted in the field of Applied Linguistics, especially by researchers working on interaction between non-native and native speakers of a language (Encrages, 1993). We are connecting three main notions: collaboration, interaction and acquisition. Indeed, research on exolingual interaction (native / non-native) intends to define what makes interaction 'acquisitional', and the occurrence of collaboration proves to be decisive. Moreover, our pedagogical approach for this particular object of acquisition fits with a collaborative mode of learning: the learner cannot become aware of the problem (choosing the right form of interrogative according to the actual communicative situation) through a traditional learning of rules, but rather through the induction of principles which a native speaker applies unconsciously.

At first, we will attempt to define more precisely what collaboration implies for acquisition (acquisition in general or acquisition of the first language) and what notions are involved when considered within the particular scope of second language learning. Secondly, we will expose how collaboration can improve computer environments for learning and how we plan to apply it to an environment dedicated to the learning of French interrogatives.

\subsection{The specificity of collaborative learning.}

Deutsch (1949) compares three categories of situations in which learners can interact in the learning task:

- cooperative learning (or 'collaborative learning'): each pupil's goaloriented efforts contribute to others' goal attainment.

- competitive learning: each pupil's goal-oriented efforts frustrate others' goal attainment.

- individualistic learning: there is no link between the goals of the different pupils; each of them is concerned with her own result and not with the results of others.

This presentation puts a very favourable light on collaborative learning since it benefits all the pupils. But we are still to define the 
various realities implied here. The learner can work with a peer or several learners; in competition with one or several learners; with other learners in competition with a computer (acting as teacher); or with a computer as a companion (in a group or on her own).

Collaborative learning has always existed, getting both positive and negative critiques (Slavin, 1983). A positive point is that learners are more concerned with correcting their errors in group work, that they seldom produce errors in their mutual corrections nor integrate errors made by other learners, that their discourse is more open to negotiation of sense and to self-repair. Yet, the following point is sometimes mentioned as an example of negative effect: if the discrepancy in cognitive capacities of the interlocutors is too important, then collaboration can be useless or even harmful to the learning process; besides, working in a group becomes relatively difficult for the more advanced learners (especially if they are not used to it). Miyake (1986) remarks that even when a solution is reached by a pair of learners, it might be internalised in different ways. Eventually, learners are sometimes more interested in the answer than in the way to get it, preventing thus a better effectiveness based on a better use of cognitive processes.

Evaluating collaborative learning is difficult because laboratory tasks are usually short and artificial, and do not reflect what is effectively done in the classroom. They cannot give a correct evaluation of the use of collaborative learning. Researchers and teachers argue that the effects of collaborative learning have not been specified from a theoretical point of view. However, a first theorisation goes back to Vygotsky's and Piaget's work (Schneuwly \& Bronckart, 1985). According to Vygotsky (1978) collaboration between children contributes to their development since their behaviour is more advanced when they are in group. Vygotsky (who studied language acquisition more particularly) introduced the notion of Zone of Proximal Development (ZPD) to refer to the difference of levels reached by a child solving a problem with an adult or on its own. The child is able to achieve many more things with the support of an adult than on his own, as long as there is only a small discrepancy between discourse levels. The ZPD makes collaboration appear as necessary to any cognitive development and especially favourable in some particular types of interaction.

According to Piaget, interaction between the actors of a task is useful as it raises cognitive conflicts that reveal reasoning errors. Many 
Piagetians advocate a greater integration of collaborative activities in schools (Slavin, 1983).

As a prologue to a further investigation of the effects of collaborative learning, let us point out that interaction between two or more people does not always imply collaboration, depending on the communicative situation. In its turn, collaboration does not always make interaction 'acquisitional'. Figure 1 displays facts or actions in interaction that are either favourable or unfavourable to acquisition.

\begin{tabular}{|l|l|}
\hline $\begin{array}{c}\text { Actions favouring acquisition in } \\
\text { interaction }\end{array}$ & $\begin{array}{l}\text { Actions hindering acquisition in } \\
\text { interaction }\end{array}$ \\
\hline $\begin{array}{l}\text { - rephrasing rather than explaining or } \\
\text { giving a definition } \\
\text { - goal/stake common to the speakers } \\
\text { - solicitation of other speaker } \\
\text { - awareness of difficulties } \\
\text { - proximity in discourse levels of } \\
\text { speakers } \\
\text { - didactic contract } \\
\text { - intake by the learner } \\
\text { - interaction of two processes (repairs and } \\
\text { self-repairs) }\end{array}$ & \\
\hline
\end{tabular}

Figure 1: facts or actions in interaction that are either favourable or unfavourable to

$$
\text { acquisition. }
$$

Thanks to some research conducted on first language acquisition (Vygotsky 1978), we are now able to identify a series of facts conditioning a good collaborative learning. How can we relate it to collaboration in second language acquisition by adults ? Piaget has shown how collaborative activities could improve the cognitive development of a child, but in the case of second language learners this development is completed. Can we then consider that collaboration has the same role in first and second language acquisitions?

\subsection{Second language as a specific object of acquisition.}

The main object of second language learning being precisely the ability to interact in that language, this production mode cannot be left aside during the process of acquisition. In fact interaction is not only an aim but also a way to learn, as mentioned by Pujol and Véronique (1990): "Second 
Language Acquisition is the process whereby a given individual learns through social interaction of some kind, the grammar and the pragmatics other than those in her ${ }^{1} \mathrm{~L} 1 . "$

However, this definition cannot in itself distinguish first language and second language learning processes. Vygotsky, who studied mostly first language acquisition, qualifies the processes as 'opposite'. His model postulates that second language acquisition is to be considered as a higher level process maturing through social interaction, a top-down process, whereas it is a bottom-up process in first language acquisition. An adult learner has already mastered a linguistic system when she starts learning a second language in which she tries to identify some components. A child discovers the linguistic system of his first language gradually.

The process of acquiring a second language is a constant move between balance and unbalance, between known and unknown systems. However, this difference with first language acquisition does not reduce the status of interaction in second language acquisition.

In his research on second language acquisition, Porquier (1982) focused precisely on the role of interaction for this acquisition, and introduced the term of exolingual interaction ('interaction exolingue' in French): interaction between a native speaker $(\mathrm{N})$ and a non-native speaker (NN). According to him, the behaviours of native and nonnative speakers contribute greatly to acquisition if there is an awareness of difficulties, self-comparison and internalisation of rules by the nonnative speaker, desire to collaborate and expectations from the native speaker, situation of problem solving, didactic contract and bifocus (focus on form or on content).

Notably, some aspects identified as favourable to acquisition in collaborative learning are again mentioned in the field of exolingual interaction: self-repair by the learner and repair by the native speaker, desire to cooperate and common goal. Our aim here is to extract what is related to collaboration in this type of interaction.

\footnotetext{
1 we attribute the feminine gender to the learner and the masculine one to the companion.
} 


\section{Exolingual interaction and the notion of collaboration.}

Research on language acquisition made a great leap forward when it began

to consider an utterance not as an isolated element but in a group of utterances such as an interaction. Indeed, exolingual interaction is one of the possible situations encountered by a second language learner. This type of interaction has thus become an object of research in Applied Linguistics (Encrages, 1993).

\subsection{Interaction within the scope of second language acquisition.}

Interaction involves several issues which should be distinguished from one another. We are especially interested in interaction as an exchange between native and non-native speakers, and as a relation to language. Research on second language acquisition sees the following positive points in interaction:

1) interaction can add a sociocultural dimension to language learning,

2) interaction allows the learner to make use of her knowledge and reconsider it if necessary,

3) learning through interaction prepares the learner to real world interaction.

Concerning the first point, first and second language acquisition differ even though interaction is essential in both. A second language learner interacts also with a different social and cultural context. Some applied linguists have focussed their research on interactions between immigrants and native speakers, which include both linguistic and sociocultural factors. Our concern is precisely to study the acquisition of an element of language which has both a linguistic (lexical and grammatical) and a pragmatic (sociocultural) dimension. The acquisition of pragmatics in a first language is implicit through interaction with other speakers; interaction with a native speaker is not the only way to acquire a second language, but it may also help to acquire its pragmatic dimensions.

The second advantage of interaction is that it allows the learner to 'show' her misconceptions. "The learner's own output serves as input to the language processing mechanisms. Deviant output that is subject to corrective feedback raises consciousness and facilitates acquisition of the 
correct forms" (Ellis, 1990). Interaction between native and non-native speakers involves both language competence and language use. Through a series of corrective feedbacks, the speakers help each other to find a satisfactory utterance. Like Grandcolas (1984), we chose to "develop activities which are likely to help the learner make the best of her limited resources, and which promote real cooperation."

Thirdly, interaction as a learning mode can also "prepare the learner to behave naturally and efficiently in conversations" (Grandcolas, 1984). Some pedagogues (Brown, 1983) advocate the learning of phrases which are particularly effective to conduct an interaction (to express a refusal to cooperate, an agreement, a doubt, a need for clarification or precision, etc.)

Research in Linguistics (and here Applied Linguistics) has devoted a large place to interaction, as research in Psychology of Education has to collaboration. Besides, we know that these two notions are closely intertwined. What we have learned from these research fields should help us understand the role of collaboration in the process of learning a second language.

\subsection{Collaboration and exolingual interaction.}

Studies on exolingual interaction have defined a new concept: 'séquence potentiellement acquisitionnelle' (SPA, which means 'potentially acquisitional sequence'). An underlying hypothesis is that inside an interaction some sequences seem to make use of principles which are inherent to acquisition. A SPA would then be favourable to acquisition. For Py (1989), "it is necessary [...] to make possible and efficient the cognitive processes of focus, attention, questioning, analysis of discrepancies, relation to other existing rules." He adds that the acquisitional potentiality of a sequence is greater if the learner is in a period comparable to Vygotsky's ZPD, when her interlanguage is more liable to benefit from such sequences.

Figure 2 shows a prototype of a SPA such as it was proposed by Py (1989): the non-native speaker is in difficulty and solicits the native speaker who gives her an information, the $\mathrm{NN}$ takes the help and the $\mathrm{N}$ gives her approval.

This prototype raises a major question: how can we identify a SPA ? How can we know if the solicitation by the non-native was well understood by the native and the help given by the native was taken 
appropriately ? How can we be sure that there has been acquisition and not only continuation of the interaction?

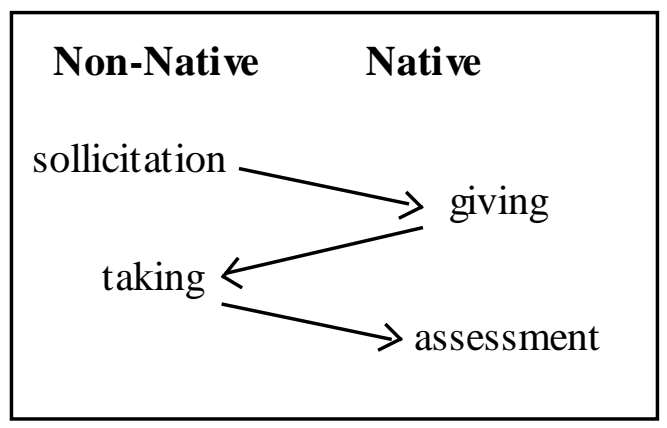

Figure 2: Prototype of a SPA

Most studies on exolingual interaction take the following elements as characteristics of a SPA: bifocus on form and content, interactive mutual adjustments, givings ('données': information given by the native to the non-native), takings ('prises': integration of the givings by the nonnative), effort to collaborate and to have a didactic attitude, repairs and self-repairs.

The attitudes of both native and non-native speakers condition the value of the sequence. At a deeper level, Bartning (1991) distinguishes several degrees of acquisitional potentiality, depending on whether the sequence is local or occurs several times in the corpus. Several reproaches can be addressed to the community studying exolingual interaction:

- they introduced some primitives which are meant to describe a SPA, but did not try to formalise them.

- they did not clearly try to identify a way to evaluate whether acquisition had occurred. We consider that a good sign of acquisition has occurred when the learner re-uses a new form in an appropriate manner.

- their study of interaction is conducted a posteriori, as an observation with no concern for prediction. In order to modelise a SPA, we need to consider a whole range of forms of interaction and predict which ones are more potentially acquisitional.

Native speaker / non-native speaker collaboration is underlying in those sequences and proves to be a main acquisitional factor. A computer environment for second language learning should thus integrate 
the notion of collaboration between two actors of an interaction. In the environment we are developing to help the acquisition of pragmatic knowledge in a second language, learner and computer are those actors who try to reach an objective by interacting in French.

\section{A computer environment for a collaborative second language acquisition.}

Collaborative learning has recently appeared as a new preoccupation for researchers who wanted to escape the traditional architecture of Intelligent Tutoring Systems (Wenger, 1987) and build computer environments which would avoid the tutor/learner model. Several examples exist already, which address the question of learning in general but not of second language (L2) learning. We will explain how L2 learning can benefit from a collaborative form of computer-assisted learning, and will illustrate our theory with examples from our environment.

Various studies were devoted to the integration of collaborative learning in computer environments for learning, sometimes leading to the development of systems. Although they are advocating collaboration in learning, these studies have all underlined the difficulties of its application. We have retained some of the main ideas which we consider within the scope of second language learning. Two questions have to be addressed: why and how to integrate collaboration in our learning environment?

\subsection{Why include collaboration ?}

As pointed out in the literature referred to hereafter, collaboration:

- allows the learner to be an actor in the computer environment.

- allows the learner to access an expert's knowledge (the knowledge of a native speaker) when she really needs to. Firstly, she has to be aware of the occurrence of a difficulty and know that another possibility may exist.

- encourages interaction, which involves an acquisitional potential.

Collaboration is beneficial for tasks that give rise to a conflict of hypotheses between both participants of the interaction, or where participants have to build something together (O'Malley, 1992). A 
learning environment has no pre-defined path; it is explored by the learner who tries to reach a goal by interacting with the companion. The dialogue can involve some conflict of hypotheses. However, being aware of errors is only beneficial to the learner if she understands what provoked them. Dillenbourg and Self (1992) propose a model which they consider as "an object to think with". By conducting a transparent reasoning, the companion helps the learner understand the cognitive processes of an expert and infer strategies which can support her learning. In this case, collaboration may help the learner become aware of all the processes and strategies involved in learning (Bull, 1993).

In any collaborative working session, interaction involves sociocultural aspects: the roles of the participants influence the planning of the dialogue. Can there be an interaction when the companion is a computer ? It seems so if we consider that, according to Blaye \& al. (1992), users can assign a social behaviour to the computer, that is to adopt specific attitudes according to their idea of the system. Collaboration should be even easier as the companion-system has an advantage on the native speaker: it is well defined, stable; the learner has a clear image of him. This neutrality of the system is likely to help the learner express her difficulties openly. Yet, researchers in the field of CAL are not all convinced of the validity of collaborative learning in computer environments. The next section is referring to one particular environment that claims to be collaborative, and from which we start specifying an idea of a computer environment for language learning.

\subsection{How to make the best of collaboration?}

In the first part of this paper, we selected a series of positive attributes of collaborative learning: learners are more aware of their errors, open to negotiation, motivated by a goal. We have had to make a series of choices to assign similar attributes to our learning environment. Among the various existing forms of interaction including learners and computers, one interested us: interaction with a computer system (not 'around' or 'through' the system (O'Malley, 1992)).

The learner may solicit the system if she wants, and the system may in its turn solicit the learner and start an interaction. The system's decision depends on the learner model it has gradually built. The status of the learner and the companion are equal, which should prevent any pressure being put on the learner; indeed the companion-system is to 
make the learner reach a solution and not to make her accept its solution.(Cumming \& Self, 1989-1991; Dillenbourg \& Self, 1991).

The architecture of the system should be flexible, as specified here: the learner-companion pair can take various routes according to the results of negotiations. The learner is to go along a complex structure which she apprehends step by step, selecting new strategies according to her level of advancement. Chan (1992) proposes such an architecture (a 'curriculum tree') for the system Integration-Kid which includes an agent 'teacher', an agent 'learner' and an agent 'companion'. The curriculum tree is composed of nodes 'episodes' and nodes 'scheduling nodes', the latter being in charge of conveying some information to the next episode. For each episode the major issues are the representation agents have of each other and their interaction. This interaction of agents constantly building representations of each other matches our idea of a collaborative environment for language learning.

Yet, the learner will only try to explore the structure if she is motivated. According to Chan (1993), motivation appears "when the learner can actively have an effect on his environment." Learning is a social process occurring almost naturally through interaction with the learning object and the actors involved with that object. This view of learning as a social phenomenon has long been advocated by researchers in psychology, but never taken into account by traditional intelligent tutoring systems. Recently, it has started to interest people from this field: Cumming, Dillenbourg, Self, and Chan are representative of this new trend. However, none of their works was concerned specifically with second language learning.

The specificity of this acquisition forces us to make certain choices in the elaboration of the environment. We know that collaborative learning implies bifocus (the learner's attention is focusing on two things: content and form); the planning of this bifocus by the companion forces us to make a pedagogical choice: even though learning a second language means learning the form rather than the content, favouring the content may be more appropriate sometimes in order to transmit the message. A good learner model and a historic of the working session can provide the companion with clues to make this type of choices.

More questions arise about the possibility to have the companionsystem identify a solicitation, a taking, an acquisitional sequence or decide to go on with the interaction. Moreover, learners can have varied 
behaviours and solicit the companion more or less often. The prototype of a SPA is not that easy too integrate in a collaborative computer environment: if the learner has to elicit very clearly each solicitation (instead of using intonation or pauses like in a natural situation), then she might give up the very idea of a solicitation. Even more, eliciting a difficulty is sometimes sufficient to find its explanation: collaboration would then no longer be justified.

A 'bad' interaction is usually due to a difference in the perception of what the goals should be. "Ideally, student and Intelligent Cooperative System are partners [...] both have the common goal of solving a problem [...]. The path to a solution is a matter of debate." (Kanselaar \& Erkens, 1993). Therefore, it might be necessary to reaffirm those goals during the working session. Clearly, it is a hard task to reach a state of interaction that is both enriching and almost natural.

At the more general level of the system's development, we address the question of a possible need to vary the amount of cooperation according to the activities and competence levels of the learner: less collaboration above a given level but more for some types of activities.

\section{ELEONORE: an environment for the acquisition of direct interrogatives in French as a second language.}

Our paper is centred on the computer-aided learning of French interrogatives by English speakers. We have chosen the domain of interrogative sentences because these linguistic forms play an important rôle within language interaction. Their grammatical structures in French are more varied than in English. In this example, four forms are possible in French whereas one only exists in English:

Where is the restaurant?

Où se trouve le restaurant?

Où le restaurant se trouve-t-il ?

Le restaurant se trouve où ?

Où est-ce que le restaurant se trouve? 
Figure 3: the learner selects some pragmatic parameters and the system gives a graded selection of utterances matching the communicative situation.

The variety of interrogative forms in French is directly connected to multiple sociolinguistic uses. Hence different levels of knowledge (grammatical and pragmatic) and competence interweave (Renié, 1992).

Therefore, ELEONORE - the computer environment we are developing (Chanier \& Renié, 1993)- intends to help advanced second language learners acquire a complex competence on interrogative sentences. Collaboration is one of the learning modes proposed in ELEONORE. It is employed in the last activity of the environment, on which we focus in the following sections. 


\subsection{Presentation of the computer environment and focus on the collaborative activity.}

Considering the complexity of the domain to acquire, ELEONORE is proposing activities in various modes (discovery mode, exercise mode, explanation mode and collaborative mode).

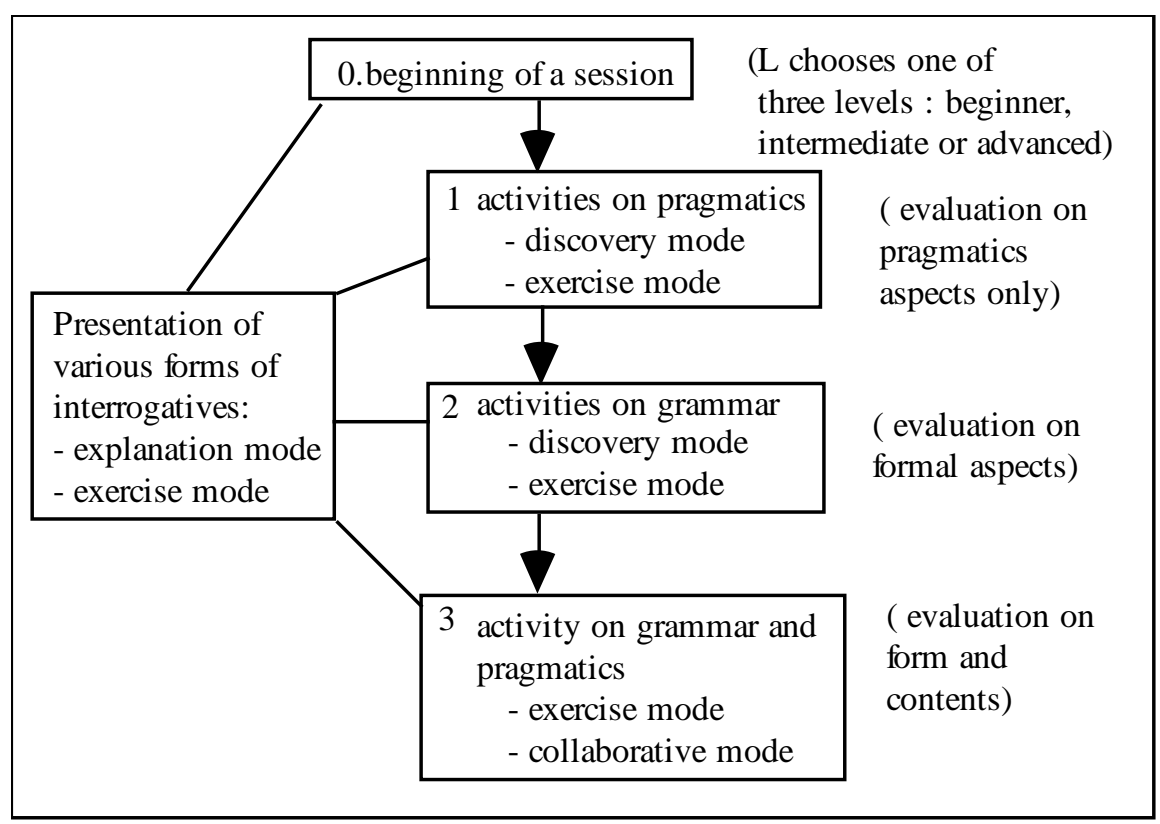

Figure 4: periods of evaluation in a working session of ELEONORE.

The activities centre on two aspects: pragmatics and syntax. Both aspects are treated separately first, then simultaneously, through three ordered sequences of activities (Figure 4):

- 1) learning pragmatic parameters. At this first stage only comprehension and selection of parameters are required (Figure 3 displays an activity in which the learner discovers pragmatic aspects of the production of interrogatives sentences).

- 2) mobilising grammatical competence to produce interrogatives in context. This stage focuses on production: the learner does not select the pragmatic parameters but knows how the system does it after going through stage one,

- 3) selection of parameters and production: mixed mode of comprehension and production relying simultaneously on syntactic and pragmatic knowledge. 
In 3), the learner has to make use of the knowledge acquired in 1) and 2). The first two sequences of activities are fully implemented, whereas the collaborative activity of the third one is being implemented. In the collaborative mode, a companion guides the learner by answering solicitations or possibly warning her that she is wrong. Moreover, working in collaboration can help the companion identify the learner's error: if the learner does not produce the expected utterance, the error might relate to misconceptions on a pragmatic or syntactic level.

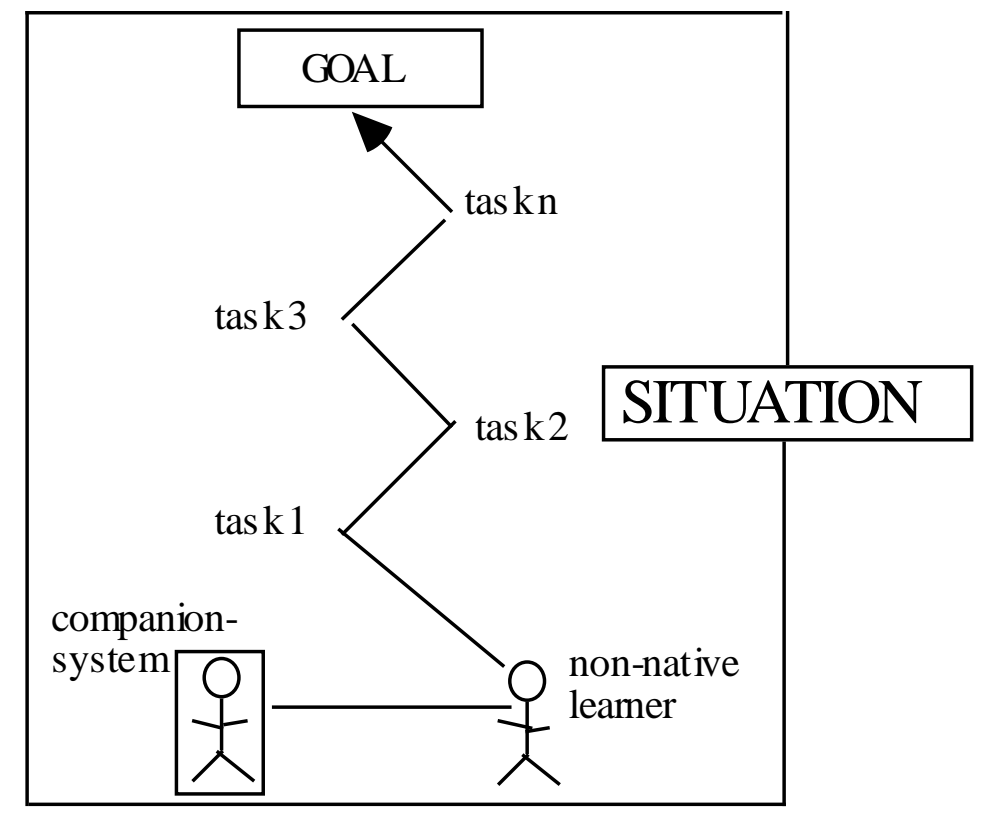

Figure 5: working session with collaboration between non-native learner and companion-system.

In figure 5, we illustrate our view of a working session (in the third sequence of activities, collaborative mode), the native speaker acting not as a mere support but as a 'fellow traveller'. Our approach of the acquisition of interrogatives in French involves a pragmatic dimension: differentiating the uses of such or such form according to sociolinguistic parameters which are not identical across languages. The companionsystem is an expert and a guide: it has some knowledge on the domain like any native speaker has, and is willing to help. Therefore, he will take a didactic attitude and interact on two levels (on the task and on the linguistic form). 
For a sample of different communicative situations, we propose some scenari in which the non-native learner is one of the actors of the dialogue. The learner can only reach her goal once she has asked the appropriate questions, that is questions which suit the pragmatic criteria associated with the situation (criteria which she has to infer). For each situation ('Au restaurant', 'Au bureau', 'A la maison' / 'At the restaurant', 'At work', 'At home') a goal has been determined. To achieve it, the learner (with the companion) must go through several steps; the companion is here to collaborate by giving information, supporting or warning the learner. As an example, we present here a scenario for 'Au restaurant', in which the companion system asks the learner to telephone a restaurant and get some information in order to book a table (figure 6):

- scenario: conversation on the phone between the owner of a restaurant and a future customer.

- role of the learner as an actor in the dialogue: future customer.

- goal: to book a table in the restaurant.

- sub-tasks: the learner is to ask:

. whether the restaurant is open on Sundays,

. whether it is also open on Sunday nights,

. whether there is a non-smoking room,

. the owner of the restaurant to book him a table. (step 4)

The scenario can be split into four successive steps. Step (2) is displayed on the screen only once step (1) is passed. In case of failure, the companion will decide to collaborate with the learner. In figure 6 , the utterances of steps 1,2 and 3 are requests for information whereas in step 4 it is a request for action.

From now on, we will give some examples of interactions that could occur in step 2: the learner has just been told that the restaurant is open on Sundays, and asks about Sunday nights. She has to infer all the criteria imposed by the parameters of the situation and find the right question to ask on the base of the utterance in bold.

The expected answer is:

Vous ouvrez aussi le dimanche soir ?

(Are you also open on Sunday nights ?)

If the learner asks:

Est-ce que vous ouvrez aussi le dimanche soir? 
(1) - Allô !

- Allô, c'est le restaurant l'Aubergade ?

is this the restaurant l'Aubergade?

- Oui, bonjour.

Yes, good afternoon.

- Je suis M. Jones. Je vous appelle parce que je voudrais venir avec un groupe d'amis, cette semaine.

My name is Mr Jones. I am calling you because I would like to come with a group of friends this week.

- D'accord, mais je vous conseille de réserver.

Yes, of course, but I would advise you to book a table.

- Bien sûr.

Sure.

(demander si le restaurant ouvre le dimanche.)

(ask if the restaurant opens on Sundays.)

(2) - Oui, nous ne fermons que le lundi.

Yes, we are closed on Mondays only.

-..........................................?

(demander s'ils ouvrent aussi le dimanche soir.)

(ask if they are open on Sunday nights as well.)

- Oui, midi et soir. Vous prévoyez de venir dîner, donc ?

Yes, for lunch and dinner. Are you planning to come for dinner, then ?

- Oui, c'est ça.

Yes, indeed.

(3) - Combien serez-vous ?

How many people will there be?

- Six.

-.......................................................?

(demander s'il y a une salle non-fumeurs.)

(ask if they have a no-smoking room.)

- Oui, bien sûr.

Yes, of course.

(4)

(demander au restaurateur qu'il vous réserve une table pour le dimanche soir.)

(ask the owner of the restaurant to book a table for Sunday night.)

- D'accord, pour quelle heure?

Yes, for what time?

- 21 heures, si c'est possible.

9 o'clock, is it alright?

- Pas de problème, alors à dimanche M. Jones!

Yes that's right, see you on Sunday Mr Jones then!

- A dimanche, merci !

Figure 6: 'Au restaurant': telephoning to book a table. The text is displayed step by step to the learner who fills it by asking the utterances in bold characters appropriately. 
The companion may:

- remark that the question is about a topic being developed, therefore it is better to avoid using 'est-ce que' which is used more to initiate an exchange or to emphasise an utterance.

- remark that this utterance does not sound 'natural'.

- propose an utterance which he finds more appropriate.

These three possible reactions can either make the learner solicit the companion, proceed to a self-repair or continue the interaction. According to the learner's level and the process of the learning session, the companion will choose to give a certain type of help. The level is set at the beginning of the session by the learner herself, but may be reset during the session according to her performance. The learner model takes into account the type of help solicited by the learner, and the frequency of her solicitations:

- help on content,

- help on form,

- partial help,

- full help (answer is given).

This information on the learner's behaviour allows the system to decide on the direction to take. But here again the learner can decide to negotiate if she has a specific desire. ELEONORE offers a constant possibility of negotiation both on the task and on the linguistic levels. This two-level configuration characterises any natural situation of exolingual interaction. A simplification of the goal to reach (suppressing or simplifying some tasks) is possible if the companion finds it necessary.

The learner may have misconceptions on both linguistic and pragmatic levels: she does not choose the appropriate syntactic structure and her utterance is erroneous. Should the companion correct the choice of structure or the syntactic error ? He may decide that at this point of the interaction only the task counts, and the utterance needs only to be understandable. On the other hand, he may use this opportunity to correct the learner on the linguistic level (i.e. grammatical level and/or pragmatic level). Collaboration enables thus a better conformity between what the learner is capable of doing and the tasks she has to achieve. 


\subsection{Applying the model of a SPA to the interactive situation proposed in ELEONORE.}

On the base of the prototype of a SPA proposed by Py (section 2.2., figure 2), we have imagined a series of possible interactions between the learner and the companion for the same step of the same scenario as above. We will use these sketches as a base to represent interaction in a collaborative activity of ELEONORE.

In order to characterise the utterances of the native speaker and nonnative learner, we borrowed the terminology used in studies on exolingual interaction (some terms were literally translated for the purpose of this study):

approval (App): the learner retains the solution expressed by the native companion or the companion confirms the self-repair made by the learner.

giving (Giv): the companion expresses a giving when he gives an information after a solicitation or an incomprehension. The learner expresses a giving when she produces an utterance.

incomprehension (Inc): the learner expresses her non-comprehension of a solicitation, a repair or a giving of the companion; or the companion expresses his non-comprehension of a solicitation, a self-repair or a giving by the learner.

mention (Men): the companion gives the solution to the learner after a solicitation or an incomprehension. (Men is only for the companion).

solicitation (Sol): the learner needs a giving from the companion, or the companion wants to identify a possible learner's error. Bartning (1991) distinguishes implicit solicitation (intonation, pause...) from explicit solicitation. As the learner is interacting through the keyboard, only explicit solicitation is considered here.

Due to the impossibility to predict that an utterance will be a taking (section 2.2.), we choose to refer to 'givings', knowing that these utterances can be correct or erroneous. Note that each participant may produce any kind of utterance except for the mention, which can only be expressed by the companion. 


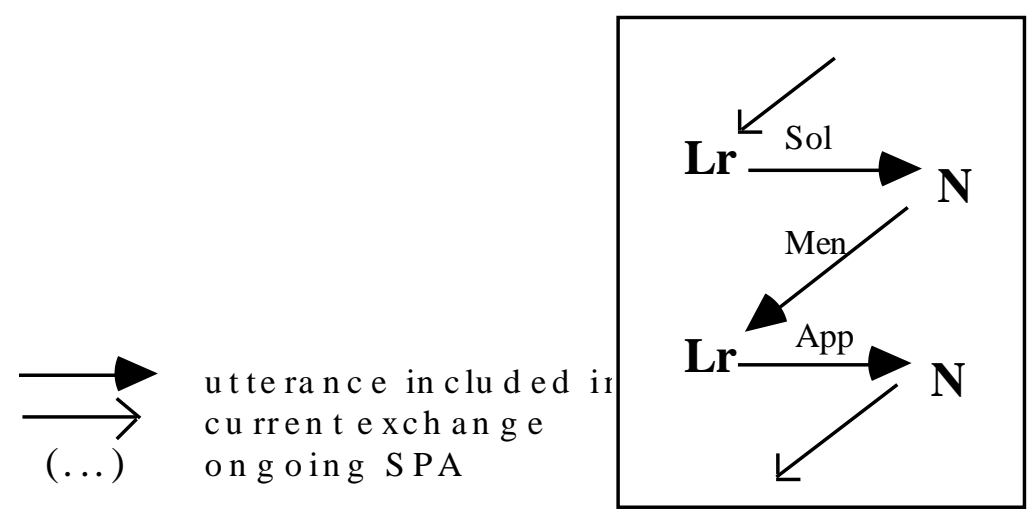

Sketch 1: interaction with solicitation by Lr, mention by $\mathrm{N}$ and assessment by Lr.

Sketches 1 to 3 illustrate three possible structures of a SPA. In sketch 1 , the learner $(\mathrm{Lr})$ initiates the sequence.

Example 1.1. (on form):

Sol(Lr): Comment on pose cette question ?

Men(C): Je poserais la question ainsi: Est-ce que le restaurant ouvre le dimanche ?

App(Lr): D'accord. Est-ce que le restaurant est ouvert le dimanche ?

(Translation:

Sol(Lr): I don't know how to ask that question .

Men(C): I would ask it that way: Est-ce que le restaurant ouvre le dimanche?

Ass(Lr): Okay. Est-ce que le restaurant ouvre le dimanche ? )

The acquisitional potential of the sequence represented in sketch 1 is weak or non-existent. Lr integrates the information temporarily but will not be able to use it again appropriately (cf. Bartning, 1991, page 13, example 3).

In sketch 2, the native companion initiates the sequence: 


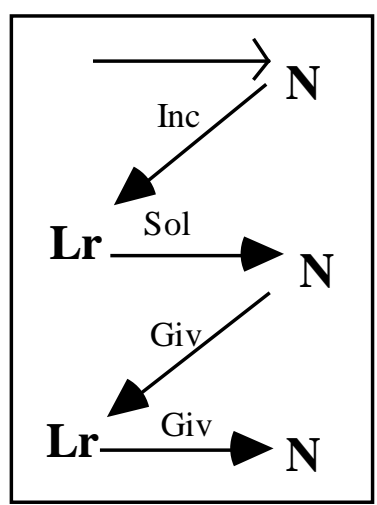

Sketch 2: interaction with incomprehension by $\mathrm{N}$, solicitation by Lr, giving by $\mathrm{N}$, giving by Lr.

Example 2.1 (on form):

Inc(N): Je ne comprends pas ce que tu veux dire.

Sol(Lr): Comment on pose cette question?

Gi(N): Dans ce cas il suffit d'ajouter 'est-ce que' .

$\mathrm{Gi}(\mathrm{Lr})$ : Est-ce que le restaurant ouvre le dimanche?

(Translation:

Inc(N): I don't understand what you mean.

Sol(Lr): How do you ask that question ?

Gi(N): In that case you just have to use 'est-ce que' .

$\mathrm{Gi}(\mathrm{Lr})$ : Est-ce que le restaurant ouvre le dimanche ?)

\section{Example 2.2 (on content):}

Inc(N): Je ne comprends pas ce que tu veux dire.

Sol(Lr): Je ne comprends pas bien l'ensemble de la situation.

$\mathrm{Gi}(\mathrm{N})$ : C'est ta première question dans l'échange, alors utilise 'est-ce que'.

$\mathrm{Gi}(\mathrm{Lr})$ : Ah, oui. Est-ce que le restaurant ouvre le dimanche ?

(Translation:

Inc(N): I don't understand what you mean.

Sol(Lr): I don't quite understand the overall situation.

$\mathrm{Gi}(\mathrm{N})$ : This is your first question in this exchange. It would be better to start with

'est-ce que'.

Gi(Lr): Oh,ok! Est-ce que le restaurant ouvre le dimanche ?)

On the basis of these sketches, more can be obtained; when $\mathrm{N}$ is initiating the sequence, he can be found not in a situation of incomprehension but of solicitation (sketch 3); $\mathrm{N}$ can then become the instigator of an exchange similar to example 2 : 


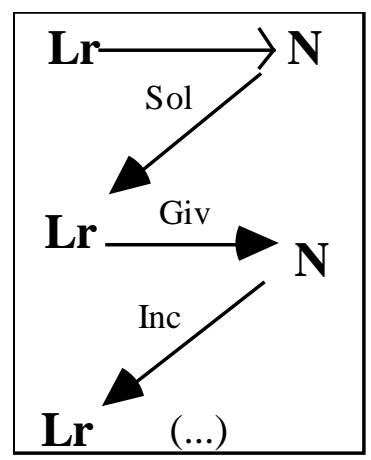

Sketch 3: $\mathrm{N}$ is in a situation of solicitation

Example 3.1 (on form):

Sol(N): Quelle est ta difficulté ?

Giv(Lr):... le dimanche... ?

Inc(N): Je ne comprends pas ce que tu veux dire.

Sol(Lr): Comment on pose cette question ?

Gi(N): Dans ce cas il suffit d'ajouter 'est-ce que' .

$\mathrm{Gi}(\mathrm{Lr})$ : Est-ce que le restaurant ouvre le dimanche ?

(Translation:

Sol(N): What is the problem?

Giv(Lr):... on Sundays... ?

Inc(N): Sorry?

Sol(Lr): How do you ask that question?

Giv(N): In that case you just have to use 'est-ce que'.

Giv(Lr): Est-ce que le restaurant ouvre le dimanche ?)

Of course, a SPA can be embedded in another SPA. In order to consider a variety of sequences, we have written a basic 'grammar' of a SPA (Figure 7) which is launched at the very beginning of the collaborative activity of ELEONORE and runs all through it. 


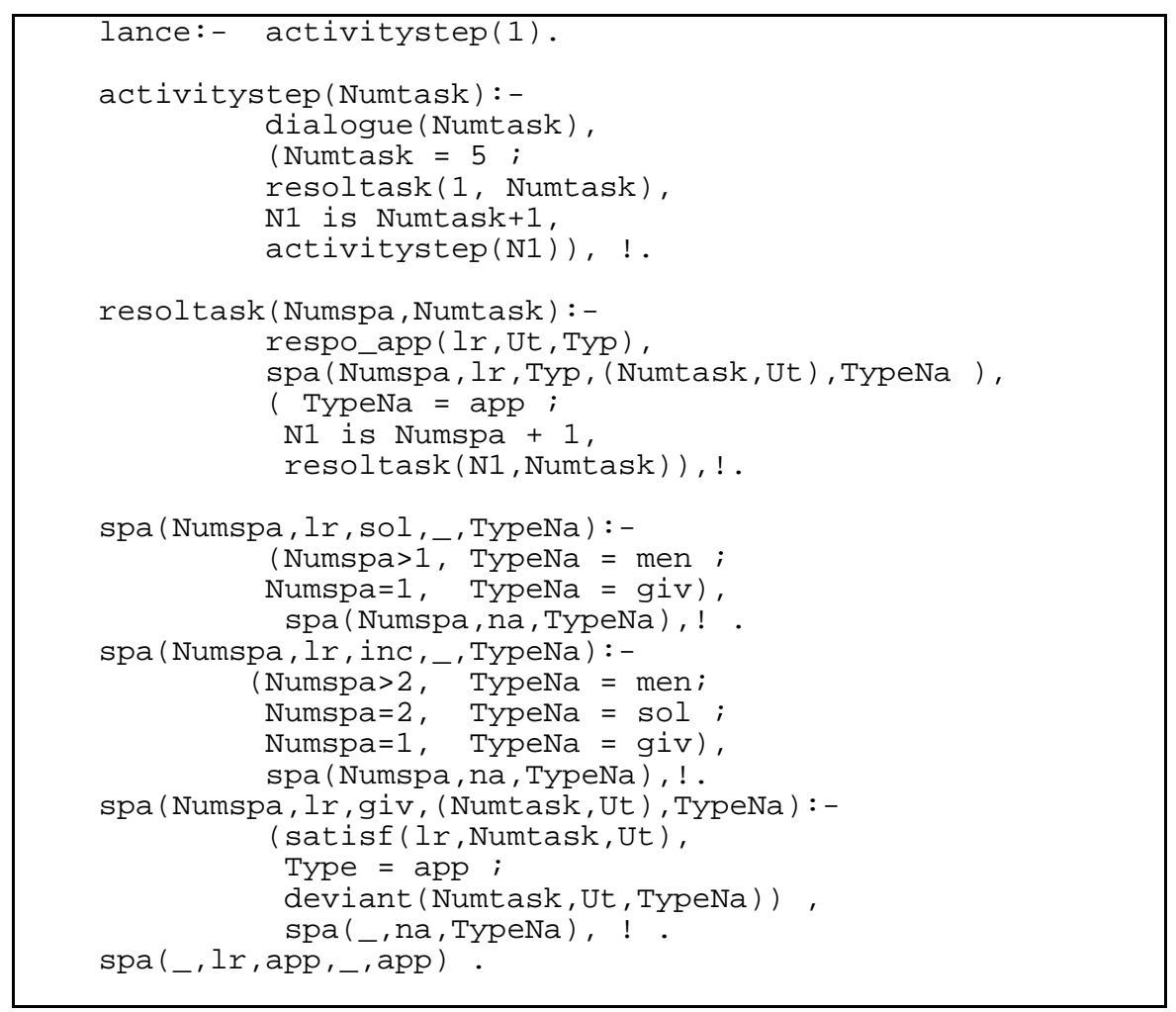

Figure 7: summarised grammar of an interaction including one or more SPAs. The subgrammar defining the native's SPAs is not presented here. "lr" stands for "learner" and "na" for "native".

The main functions of the program are explained here:

- 'lance' launches the program.

- 'activitystep' displays the five parts of the dialogue one after the other, and launches the four tasks.

- 'dialogue' displays the parts of dialogue.

- 'resoltask' solves each of the four tasks.

- 'spa' runs an interaction involving an utterance from the learner followed by an utterance from the native. According to the number of utterances proposed by the learner to solve a same task, the native companion decides on the type of utterance to produce.

- 'satisf' and 'deviant' test whether the utterance of the learner is expected or not.

- the interaction is completed when one of the speakers produces an approbation (app). 
An interaction is considered more or less acquisitional according to the types of utterances and their frequencies. At the level of the main dialogue (Figure 6, section 4.1), we consider that there has been acquisition if the learner re-uses an information (a giving) received on a previous step.

\subsection{Status of the native companion in ELEONORE.}

The companion in ELEONORE is in charge of planning the interaction by taking into account the historic of the learner (the frequencies of the various types of utterances, the learner's performance) and the goals set at the beginning. In specifying the status of the companion in the collaborative task we take into account the competence of the learner and the development of the interaction.

\section{Function and nature of the companion in the interaction.}

The companion has two functions: one is to achieve a goal which is shared with the learner: 'to book a table in a restaurant', for instance. The companion stands as a native speaker collaborating with the learner. The second function is to use what ELEONORE acquires about the learner throughout a working session in order to start a didactic contract with her. For instance, the frequency of her calls to the companion gives an indication of her tendency or need to collaborate. On the base of this information, the companion will decide how to conduct the interaction.

The following three main points characterise the nature of the companion:

- the companion's knowledge on interrogative sentences is that of a native speaker of French: his competence is both pragmatic and grammatical.

- the companion has various kinds of information on the learner thanks to its learner model (cf. hereafter).

- he is a good pedagogue (he is attentive to what the learner is doing, always aware of the goal to reach, and knows how to communicate.)

Stereotype of a learner acquiring the interrogative sentences of French as a second language.

To assist the acquisition of interrogatives - especially in collaborative activity - ELEONORE requires some knowledge on the difficulties of 
this acquisition and the steps it comprises. Most studies in this domain concern English. As a whole, very few of them have taken into account the pragmatic dimensions of these forms.

Our work consists partly in doing a longitudinal experimentation with learners of French as a second language in France. This experimentation will allow us to validate or invalidate our hypotheses, and from thereon to select the information necessary to build the learner model (concerning both her pragmatic and grammatical competence) which will be used by the companion.

\section{Learner monitoring.}

Throughout the working session with ELEONORE, the learner is involved in activities related to two types of competence (pragmatic and grammatical). The model will be updated and refined in view of the learner's performance (for an overview of a working session, cf. figure 4, section 4.1).

Firstly, the learner assigns herself one of the three learning levels, indicating thus to the system what stereotype to select and what type of interaction to choose a priori (number of tries, form of support). In view of the learner's performance, the system may decide to recommend another level to her.

More precise and punctual, information on grammatical and pragmatic activities provides the learner model with data on the acquisition of grammar and pragmatics. Both groups of activities offer a discovery mode and an exercise mode.

In the collaborative activity presented in figure 6 (step 4), the companion will make use of the model built from the previous activities and supplement it with observations on the learner's ability to use a double competence: concerning form, we will have a first bifocus on pragmatics and grammar; at the more general level of the interaction, we will have a second bifocus on form and content.

The current development of our learning environment focuses on two tasks: the design of the interface to facilitate collaborative dialogues, and the elaboration of the learner model. Once they are completed, the implementation of this last activity of ELEONORE will be possible. 


\section{Conclusion}

Our first period of investigation of the works done on collaboration in learning within the field of Psychology of Education has drawn a fairly clear but general image of collaborative learning. Moreover, studies in CAL which have considered that form of learning have constituted a base for the specification of a computer environment dedicated to language learning. Our problematic centred on three main notions: collaboration, interaction and acquisition. The question we addressed was: how could there be collaboration in an interaction so as to favour the acquisition of a second language ? The object of acquisition here (interrogative sentences in French) included the learning of both pragmatic and grammatical dimensions of language. We have conceived a computer environment (ELEONORE) to help this acquisition; in a first time, the learner works on one dimension at one time, then she has to take into account both grammar and pragmatics. The collaborative working mode proposed in ELEONORE allows the learner to interact with a simulated companion whose knowledge of interrogatives in French reflects that of a native speaker. The learner needs to ask various questions to accomplish something with the companion. The latter has a didactic contract with her and can help her through difficulties on form, content, grammar or pragmatics. This interaction may take various forms and be more or less acquisitional, as we have shown it. However, collaboration (one among several working modes in ELEONORE) appears to offer a new approach of the computer assisted acquisition of a multi-level competence by a second language learner. Its effectiveness will be evaluated in an experimentation involving second language learners working with ELEONORE.

\section{References}

Bartning I. (1991): "L'activité interactionnelle dans une étude longitudinale de l'acquisition du français langue étrangère - quelques observations." Actes du 8ème colloque international Acquisition des langues: perspectives et recherches. Laboratoire de Linguistique et de Didactique des Langues Etrangères et Maternelles (ed), Grenoble (France), 123-37.

Blaye A., Light P., Rubtsov V. (1992): "Collaborative learning at the computer. How social processes "interface" with human-computer 
interaction." European Journal of Psychology of Education, vol 7, $\mathrm{n}^{\circ} 4,257-67$.

Brown G. (1983): Teaching the spoken language, an approach based on the analysis of conversational English. Cambridge University Press.

Bull S. (1993): "Towards user/system collaboration in developing a student model for intelligent CALL." ReCALL, nº 8 , 3-8.

Chan T.-K., Baskin A. (1988). "Studying with the Prince." Proceedings of the first international conference, Intelligent Tutoring Systems 88, Montreal, Canada, 194-200.

Chan T.-K. (1991). "Integration-Kid: A Learning Companion System." Proceedings of the 12th International Joint Conference of Artificial Intelligence, Sydney, Australia, Morgan Kaufmann Publishers, 1094-1099.

Chan T.-K. (1992). "Curriculum Tree: A Knowledge-Based Architecture for Intelligent Tutoring Systems." Proceedings of the 2nd International Conference of Intelligent Tutoring Systems, SpringerVerlag, 140-147.

Chan T.-K., Chien-Chang L., Shi-Jen L., Hong-Chih K. (1993). " OCTR: A Model of Learning Stages." Proceedings of theWorld Conference on Artificial Intelligence in Education, Edinburgh (Scotland), 257264.

Chanier T., Pengelly M., Twidale M., Self J. (1992). "Conceptual Modelling in Error Analysis in Computer-Assisted Language Learning Systems". In Intelligent Tutoring Systems for SecondLanguage Learning, Swartz, M. \& Yazdani, M. (eds). New York: Springer-Verlag, 125-150.

Chanier T., Renié D. (1993): "Modelling language usage to enhance second language learning." Proceedings of theWorld Conference on Artificial Intelligence in Education, Edinburgh (Scotland), 265-272.

Cumming G., Self J. (1989): "Collaborative Intelligent Educational Systems", in: Bierman D, Breuker J \& Sandberg J (eds): Proceedings of Artificial Intelligence and Education, IOS, Amsterdam., 73-80.

Cumming G., Self J. (1991): "Learner Modeling in Collaborative Intelligent Educational Systems.", in: Goodyear P (ed): Teaching Knowledge and Intelligent Tutoring., Ablex, Norwood, NJ, 85-103.

Deutsch M. (1949). "A theory of co-operation and competition." Human Relations, 2(2), 129-153. 
Dillenbourg P, Self J. (1991): "Designing Human-Computer Collaborative Learning", in O'Malley C.(ed), Human-Computer Collaborative Learning, Berlin: Springer-Verlag.

Dillenbourg P., Self J. (1992): "People Power: A Human-Computer Collaborative Learning System." Proceedings of the second international conference, Intelligent Tutoring Systems 92, Montreal - New York: Springer-Verlag.

Ellis R.(1990):Instructed second language acquisition. Oxford: D.Crystal \& K.Johnson.

Encrages (1993): "Interaction et acquisition d'une langue étrangère.", numéro spécial de la revue Acquisition et Interaction d'une Langue Etrangère, $\mathrm{n}^{\circ} 2$.

Grandcolas B. (1984): "Voulez-vous converser avec moi ? "Etudes de Linguistique Appliquée, n55, 68-75.

Kanselaar G., Erkens G. (1993): "Interactivity in cooperative problem solving with computers." in International Perspectives on the Psychological and Educational Foundations of Technology-Based Learning Environments. Vesniadou, Decorte, Glaser \& Mandl (eds).

Miyake N. (1986): "Constructive interaction and the iterative process of understanding.", Cognitive Science, 10(2): 151-177.

O'Malley C. (1992): "Designing computer systems to support peer learning." European Journal of Psychology of Education, vol 7, $\mathrm{n}^{\circ} 4,339-53$.

Porquier R. (1982): "Communication exolingue et apprentissage des langues." 4ème colloque international Acquisition d'une langue étrangère: Neuchâtel, 16-18 septembre (version provisoire).

Pujol M., Véronique D. (1990): "A sociocognitive model for second language acquisition." Poster presented at the IVth European Conference in Developmental Psychology, University of Stirling, August, 1990.

Py, B. (1989). "L'acquisition vue dans la perspective de l'interaction." in DRLAV, 41, 83-100.

Renié D. (1992). Les interrogatives directes du français: une approche pragmatico-linguistique. Rapport $n^{\circ} 17$, Laboratoire de Recherche sur le Langage, Dépt de Linguistique, Université Clermont 2 (France). 
Schneuwly B., Bronckart J.P. (1985). Textes de base en psychologie: Vygotsky aujourd'hui. Delachaux et Niestlé: Neuchâtel (Switzerland)-Paris.

Slavin R. (1983). Cooperative Learning. New York: Longman.

Terveen L.(ed) (1993): "Collaborative Problem Solving: Theoretical Frameworks and Innovative Systems." Workshop of the World Conference on Artificial Intelligence in Education. Edinburgh (Scotland), 23rd-27th August.

Vygotsky L.S. (1978). Mind in society. The development of higher psychological processes. Cole, John-Steiner, Scribner (eds). Cambridge, Mass: Harvard University Press.

Wenger E. (1987): Artificial Intelligence and Tutoring Systems. Morgan Kaufmann. 